\title{
Endothelial progenitor cells: a new player in lupus?
}

Sahena Haque ${ }^{1,2}$, M Yvonne Alexander $^{3}$ and lan N Bruce B $^{* 1,4}$

\begin{abstract}
Patients with systemic lupus erythematosus (SLE) have a greatly increased risk of cardiovascular disease. There is growing interest in the link between vascular damage and lupus-specific inflammatory factors. Impaired endothelial repair could account for the endothelial dysfunction in this patient group. This review describes the contribution that endothelial progenitor cells could play in the pathogenesis of premature vascular damage in this disease. The methods of isolation, detection, and characterization of endothelial progenitor cells, together with their potential role in repair of the endothelium and as a therapeutic target in SLE, are discussed.
\end{abstract}

Accelerated atherosclerosis is well recognized in systemic lupus erythematosus (SLE). The striking incidence of mortality associated with coronary heart disease (CHD) in SLE was first reported over 30 years ago by Urowitz and colleagues [1]. This observation has since been confirmed in several studies, and, overall, women with SLE have a fivefold to sixfold increased risk of CHD in comparison with women in the general population [2]. In addition to having an increased overall risk, patients with SLE are susceptible to CHD at a younger age than would be expected $[2,3]$. The exact etiology of arthrosclerosis in SLE remains poorly understood, and while traditional cardiovascular risk factors are likely to be contributory, they do not appear to fully explain the excess clinical CHD observed [4].

SLE has been shown to be an independent risk factor for endothelial dysfunction [5]. The vascular endothelium is the largest organ of the body and comprises a highly dynamic single layer of endothelial cells (ECs) that are pivotal in the regulation of vascular tone and that have

\footnotetext{
*Correspondence: ian.bruce@manchester.ac.uk

'Arthritis Research UK Epidemiology Unit, School of Translational Medicine, Manchester Academic Health Science Centre, The University of Manchester, Oxford Road, Manchester, M13 9PT, UK

Full list of author information is available at the end of the article
}

essential anti-thrombotic and barrier functions. Endothelial dysfunction represents a state of deviation from normal to a vasoconstrictive, procoagulant, plateletactivating, and anti-fibrinolytic state and is thought to have a key role in atherosclerosis and related diseases. Though found to be present in all stages of plaque progression, endothelial dysfunction is believed to be the key triggering factor in the initiation of atherosclerosis [6].

Endothelial progenitor cells (EPCs) represent a heterogeneous group of cells that are released from the bone marrow into the circulation and are thought to contribute to vascular homeostasis and endothelial repair. Although modulation of EPC numbers has been identified with cardiovascular disease or vascular trauma (which appears to be predictive of clinical coronary events in the general population), there is still much controversy regarding their true identity and role [7]. Mechanisms by which vascular damage is repaired are not well understood, but previous reports have suggested that two groups of ECs can be detected in the peripheral circulation of individuals with vascular damage. The first, a population of EPCs, is thought to be bone marrow-derived and involved in the repair of the endothelium. In addition, the vessel wall itself may be a source of progenitor cells involved in the repair process [8]. A second population of 'inflammatory' or 'activated' ECs is thought to have been shed from the endothelium following an insult and this population may generate endothelial microparticles derived from damaged ECs and have a potential role in cell signaling [9]. It is therefore believed that damage to ECs can result in endothelial dysfunction and this is thought to be critical in the formation of atheroma [6]. Understanding endothelial repair is a vital step toward developing targeted therapies for this organ system and will enhance our understanding of the mechanisms of atherosclerosis in SLE. EPC quantification may provide a useful marker to aid risk stratification within the context of SLE, in which the Framingham risk prediction model would appear to underestimate the risk of clinical CHD. The purpose of this review is to highlight the controversy surrounding the current nomenclature and definitions used in this field, so that we can strive toward reaching a consensus on the true identity and the role of this circulating cell type. We will focus on what is known 
about EPCs in the context of SLE and discuss how we may move toward exploiting this knowledge to reduce vascular complications in SLE.

\section{Characterization of endothelial progenitor cells}

EPCs were first reported by Asahara and colleagues [10] in the late 1990s as CD34+ mononuclear cells with the ability to form island-like colonies in culture. These bone marrow-derived cells were shown in a mouse model, under the influence of vascular endothelial growth factor, to have the ability to incorporate into blood vessels with experimentally induced ischemia [11]. These landmark experiments have given an important insight into circulating angiogenic cells and the biology of vascular repair. Two key methods have been used to identify EPCs. The first aims to identify cells with specific surface markers for EPCs by using flow cytometry, and the second addresses in vitro cell culture characteristics.

\section{Flow cytometry identification of endothelial progenitor cells}

Flow cytometry has been shown to have good sensitivity, specificity, and reproducibility [12], and several groups have used fluorescently conjugated antibodies to specific cell surface markers for analysis and identification of EPCs. The choice of surface markers for this cell type is the subject of much debate, and a variety of surface markers to identify EPCs have been used by different groups, as reviewed by Timmermans and colleagues [13]. The majority of studies using flow cytometry have used at least one surface marker to identify a cell of immaturity (from the broad hematopoietic cell lineage) and at least one marker to identify a cell from the EC lineage. Additionally, markers to identify cells originating from a myeloid lineage have been studied.

\section{Immature hematopoietic cells}

The most widely used marker to identify immaturity is C34 positivity. CD34 is a $110-\mathrm{kDa}$ surface marker expressed on hematopoietic stem cells; however, the exact origin and signals for differentiation of these cells remain unclear. CD34 can be detected on approximately $0.1 \%$ of circulating mononuclear cells and is thought to act as an adhesion molecule related to endothelial and hematopoietic cells [14]. CD133 is a $120-k D a$ glycoprotein expressed on progenitor and hematopoietic stem cells [15]. The exact function of CD133 is not clearly understood; however, the protein is thought to identify an immature population of EPCs. CD133 has been detected on a subpopulation of CD34 $/$ VEGFR2 ${ }^{+}$cells in the immature phase and has been shown to be no longer expressed on mature CD34 $4^{+}$VEGFR2 ${ }^{+}$in vitro, leading to the conclusion that $\mathrm{CD} 34^{+} / \mathrm{CD} 133^{-} / \mathrm{VEGFR} 2^{+}$cells represent a more mature differentiated population of ECs and that CD133 is a marker of 'early' EPCs [16]. It is possible that $\mathrm{CD} 34^{+} / \mathrm{VEGFR}^{+}{ }^{+}$and $\mathrm{CD} 133^{+} / \mathrm{VEGFR} 2^{+}$represent different subtypes of EPCs and that $\mathrm{CD} 34^{+} / \mathrm{CD} 133^{+} /$ VEGFR2 ${ }^{+}$can be used as a restricted EPC phenotype. One major disadvantage is that these triple-labeled cells represent a population of cells that are very small and therefore difficult to quantify reliably.

\section{Endothelial lineage markers}

It is widely accepted that EPCs express vascular endothelial growth factor receptor-2 (VEGFR2) - or kinase insert domain receptor (KDR) in humans - and the roles of the VEGF receptor family in angiogenesis and vasculogenesis are well recognized [17]. Other endothelial antigens include CD31 and von Willebrand factor. CD31 or platelet endothelial cell adhesion molecule-1 (PECAM-1) is known to have roles in angiogenesis, platelet function, thrombosis, and regulation of leukocyte migration through vascular walls [18]. von Willebrand factor has a role in platelet adhesion to the vascular wall injury and is a carrier protein of coagulation factor VIII [19].

\section{Myeloid progenitor cells}

Subsets of $\mathrm{CD} 14^{+}$mononuclear cells have been shown to express EC markers such as CD31 [20] and, following stimulation by angiogenic factors, express von Willebrand factor and KDR [21]. CD14 $/$ CD $34^{+}$cells display clonogenic properties in vitro, and importantly several recent studies have shown that $\mathrm{CD} 14^{+}$cells contribute to vasculogenesis [22,23]. Additionally, clinical correlations of $\mathrm{CD} 14^{+}$subsets suggest a reduction in the number of patients with left ventricular dysfunction [24]. However, in contrast to $\mathrm{CD} 34^{+} / \mathrm{CD} 133^{+}$cell numbers, $\mathrm{CD} 14^{+}$cell numbers appear not to be reduced in patients with clinical CHD or related risk factors [25]. While myeloid progenitor cells are detected in the circulation and appear to share many EPC characteristics, preliminary clinical studies would suggest a functional distinction between these subsets.

\section{Cell-counting approaches for endothelial progenitor cell analysis}

Another important factor to consider is the units in which cell populations are expressed. Some studies have favored expression of cells as a count per unit of volume of blood. EPCs are estimated to represent between $0.0001 \%$ and $0.01 \%$ of peripheral cells, making them a 'rare event' in flow cytometric analysis. Given the rarity of these events in peripheral blood and the variations in hemodilution between individuals (particularly in patients with cardiovascular disease), this measure can be misleading. Others have identified the proportion of total cytometry events acquired. This approach allows the 


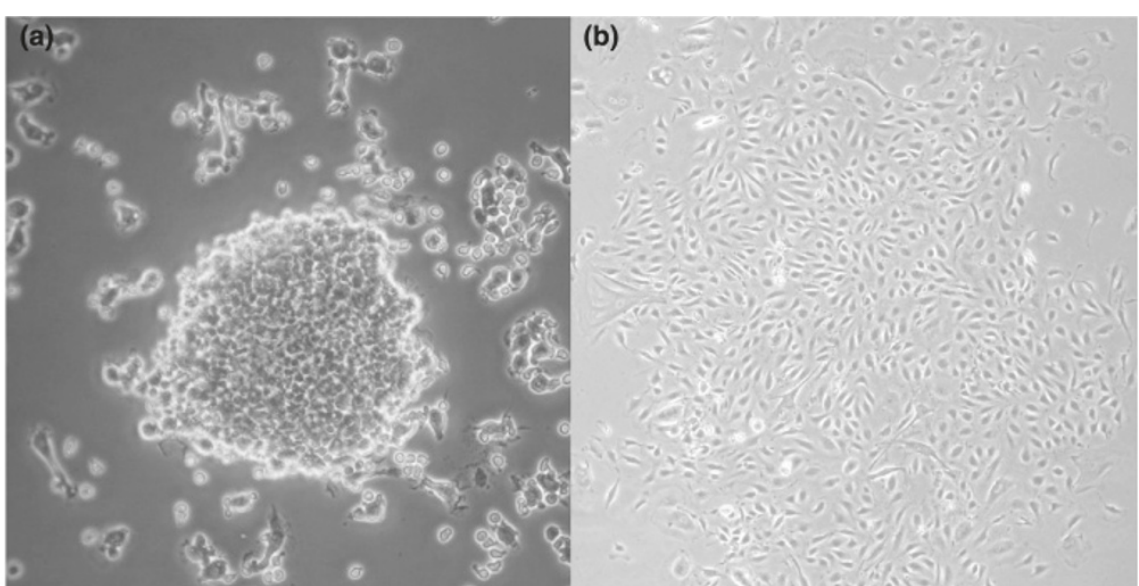

Figure 1. Colony-forming units. (a) Endothelial cell colony-forming unit. Non-adherent mononuclear cells grown on fibronectin form colonies after 4 to 9 days. (b) 'Late outgrowth' colony-forming unit. Adherent mononuclear cells grown on collagen I display a cobblestone morphology after 7 to 21 days. Magnifications: 40x (a) and 20x (b). Figure b provided courtesy of Kate Williamson.

enumeration of a proportion of a consistent number of cells counted by using flow cytometry (for example, proportion of 500,000 labeled cells analyzed). Quantifying the total number of cells may better take into account the potential for lymphopenia in patients with SLE.

Identification and quantification of EPCs by using flow cytometry can be challenging. Despite this, associations with disease states, including coronary heart disease, have been reported [7]. Specific and sensitive markers and properties to discriminate and definitively distinguish subsets of EPCs within the hierarchy of progenitor cells from mature ECs are beginning to emerge, and it has been wisely suggested that the field should adopt alternative terms for each specific subset. An alternative approach has been to identify viable cells with proliferative capacity in culture.

\section{Cell culture techniques to identify endothelial progenitor cells}

While flow cytometry is an excellent technique for the enumeration of these low-frequency EPCs in peripheral blood, cell culture, by using specific surface markers, has the advantage of allowing the expansion of cell numbers and enabling qualitative characteristics to be gathered. In the landmark publication cited above, Asahara and colleagues [10] described EPCs as in vitro cells with the ability to adhere to fibronectin and form colonies or colony-forming units (CFUs) as early as after 3 days in culture. Cells in culture were shown to have typical EC characteristics such as uptake of Dil-acLDL (Dil-labeled acetylated low-density lipoprotein) and expression of surface markers, including CD31, KDR, CD34, and Tie-2 [10]. This initial study used $\mathrm{CD}^{+} 4^{+}$- and $\mathrm{KDR}^{+}$-enriched cells in culture; however, since bone marrow EPCs fail to expand and differentiate in vitro, several investigators have subsequently used unfractionated mononuclear cells and included a pre-plating stage to increase specificity and exclude other cell types. Between 4 and 9 days after culture, this modified protocol identifies CFUs termed 'early outgrowth' colonies or CFU-Hill [26] (Figure 1). Another commonly used protocol identifies 'late outgrowth' colonies derived from adherent mononuclear cells following 7 to 21 days in culture [27].

Early- and late-outgrowth cells share a number of features, including uptake of Dil-acLDL and expression of CD31, but differ with regard to surface expression of CD133. They are likely to represent EPCs at differing stages of maturation. It should be noted that EPCs identified by using cell culture are unlikely to represent the same cells identified by using flow cytometry; however, with the aid of proteomic studies, knowledge of the precise nature of these differing EPC subtypes is becoming more refined [28]. The ultimate aim of understanding EPC biology rests with elucidating their role in vivo and whether they might be prognostic or diagnostic factors. Several groups have successfully used CFU number as a biomarker in several different disease states, including CHD-related diseases [29] and inflammatory rheumatic diseases [30], so furthering our understanding of the in vivo role of these subsets of circulating progenitor cells holds considerable promise for their clinical application.

\section{Working toward a consensus for the identity of the endothelial progenitor cell}

The observations reported by Asahara and colleagues [10] undeniably resulted in a paradigm shift within the field of vasculogenesis by highlighting the role of EPCs in 
vascular repair. Prior to experiments conducted by Asahara and colleagues in 1997, it was largely believed that 'vasculogenesis' or the de novo formation of vessels from uncommitted precursor cells occurred only in the developing fetus. However, more than a decade after the initial landmark experiments, there remains a lack of standardization regarding the identification and definition of EPCs. The use of differing surface markers and cell culture techniques between studies makes comparison of results difficult. Many groups have used CD34, CD133, and VEGFR2 surface markers in various combinations and successfully identified inverse correlations to disease states; however, recent reports have challenged the origin of cells with these markers and provide evidence that some of these cell populations, initially described as EPCs, are in fact myeloid-derived hematopoetic precursors [31]. Some investigators have advocated the incorporation of a common leukocyte marker CD45 within flow cytometric analysis and suggested that EPCs can be identified only within the $\mathrm{CD} 45^{-}$fraction of cells [32].

Cells enumerated by using flow cytometry are insufficient in number to allow the biology of the EPCs to be examined. Culture methods provide a means by which a large number of cells can be isolated but may not be an accurate reflection of EPCs in the in vivo situation. In addition, recent studies have demonstrated that other immune cell types may have the ability to mimic the morphological characteristics of EPCs in culture [33,34]. A degree of plasticity at the progenitor cell level in response to differing biological signals may explain some of these findings. It is possible that cells identified as EPCs are not directly incorporated into the regenerating endothelium but exert indirect but equally important angiogenic paracrine effects that result in endothelial repair [35]. Clearly, there is a need for studies to examine the biology of EPCs as well as elucidation of homing and differentiation signals to enable a better understanding of this unique cell type and the role of EPCs in health and disease. More methodological consistency and evidence of robust reproducibility and reliability of techniques are needed in future studies with clinical outcomes.

\section{Clinical impact of endothelial progenitor cells and cardiovascular disease}

Within the human clinical setting, a recent study has demonstrated positive outcomes in seven out of nine patients who have critical limb ischemia and who were able to avoid amputation following the intramuscular injection of autologous $\mathrm{CD} 133^{+}$cells into the affected limb [36]. Similar results have been observed by other groups that used autologous peripheral stem cells or unselected bone marrow mononuclear cells $[37,38]$. Importantly, these studies have demonstrated the safe use of cell therapy methods. Within the context of CHD, several clinical trials in the last 5 years have assessed the effectiveness of cell therapy as an adjunct to bestavailable care after an acute myocardial infarction. A controlled trial demonstrated short-term improvement of left ventricular function following intracoronary infusions of autologous bone marrow progenitor cells and sustained clinical benefit with reduced rates of death, clinical coronary event, and heart failure at 2 years of follow-up [39]. One small controlled study undertook intracoronary infusions of enriched $\mathrm{CD}_{133^{+}}$cells and demonstrated a small short-term (4 months) benefit of left ventricular function but noted an increase in coronary events (11 compared with four in the control group) [40].

Cell therapy is a growing and intriguing field, and there is evidence in several animal models that stem cell transfusion and systemic transfusion of expanded ex vivo EPCs can induce functionally intact endothelial regeneration [41]. Future studies need to consider source, purification methods, timing, and dosing of cell infusions. The sample sizes to date have been too small to assess the influence of baseline infarct size or severity of left ventricular dysfunction. Although the benefits observed to date have been modest, cell therapy in the context of acute myocardial infarction appears to be safe and shows much promise. The long-term efficacy and safety require further clarification. Whether stem cells do indeed contribute to vasculogenesis directly or result in cardiomyocyte replenishment or mediate an effect indirectly via trophic effects is not clear from clinical cell therapy studies in CHD but may be elucidated by taking a step back to laboratory experiments.

\section{Factors influencing endothelial progenitor cell generation and turnover}

Endogenous factors that influence the number and function of EPCs are of much interest. Exposure to different lifestyle factors and several pharmacological agents has been shown to influence EPC levels. Both smoking cessation and increased physical activity have been shown to be beneficial to EPC number [42,43]. Studies have demonstrated an increase in EPC number following administration of HMG-CoA (3-hydroxy-3-methylglutarylcoenzyme A) reductase inhibitors independently of cholesterol reduction and this might be another mechanism by which statin medications exert a cardioprotective effect [44]. Angiotensin-converting enzyme inhibiting agents and angiotensin 2 receptor blockers have also been shown to have a positive effect on EPC number and function in the clinical setting [45]. Other pharmacological strategies that have been shown to enhance EPC number include chemokines and cytokines such as erythropoietin and VEGF [46,47]. 


\section{Cardiovascular disease, endothelial progenitor cells, and systemic lupus erythematosus}

Over the past decade, quantitative analysis of EPCs by using both flow cytometry or cell culture experiments or both has shown that EPC numbers vary in relation to cardiovascular risk factors and atherosclerotic disease in the general population $[7,48]$, and more recently these findings have been extended to patients with SLE (Table 1). A variety of markers have been used to identify and characterize EPCs within SLE. Westerweel and colleagues [49] studied 15 women who had SLE and a mean age of 37 years ( \pm 3 years). The women, who had inactive disease for at least a year prior to the study and were taking low doses of prednisolone $(<10 \mathrm{mg})$, were compared with 15 age-matched healthy females who were $37( \pm 3)$ years old. The authors demonstrated a reduction of the overall CD34 $4^{+}$fraction of cells as well as a reduction of $\mathrm{CD}_{34}{ }^{+} \mathrm{KDR}^{+}$EPCs in patients with SLE compared with healthy controls. EPC number correlated positively with ankle brachial pressure index $\left(\mathrm{R}^{2}=0.532\right.$, $P=0.042)$ and inversely with cholesterol level $\left(R^{2}=-0.587\right.$, $P=0.021)$. There was no association with disease-related factors, including disease activity, therapy, or serological findings. Early-outgrowth colony formation/CFU was not different between the two groups, and the influence of CHD risk factors was not assessed [49]. Denny and colleagues [50] defined EPCs by using CD34/CD133 cell markers in lineage-negative cells in SLE compared with controls. The overall cohort consisted of 135 patients with SLE and 60 controls with mean ages of $38( \pm 3)$ and $41( \pm 1)$ years, respectively. It should be noted that $55 \%$ of the controls and $95 \%$ of patients with SLE were females. The authors demonstrated that a reduction of $\mathrm{CD}_{4} 4^{+} /$ CD133+ EPCs in SLE compared with controls remained statistically significant when the analysis was limited to females only. In addition, the authors documented a correlation of EPCs with the SLE Disease Activity Index (SLEDAI) $\left(\mathrm{R}^{2}=0.42, P<0.01\right)$. EPCs were shown to have a reduced capacity to differentiate into mature ECs after 7 to 21 days in culture [50]. Moonen and colleagues [51] assessed $\mathrm{CD} 34^{+} / \mathrm{CD} 133^{+}$EPCs in 44 patients who had quiescent SLE and who were $40 \pm 12$ years old and in 35 age-matched female controls who were $41 \pm 12$ years old. The authors demonstrated a reduction of $\mathrm{CD} 34^{+} / \mathrm{CD} 133^{+}$ EPCs and CFUs in SLE compared with controls. No correlation was noted between EPC or CFU number with regard to disease-related factors. CHD-related factors were not analyzed [51]. Whereas these studies all noted a reduction of EPCs in SLE, they varied with regard to clinical correlates. The populations studied were of a similar age. In a recent study, Baker and colleagues [52] investigated the correlation of EPCs with subclinical atherosclerosis. In this small study, a reduction of CD34 $\%$ $\mathrm{CD} 133^{+} / \mathrm{VEGF}^{+}$cells was demonstrated between patients with SLE and age-matched healthy controls; however, the numbers of $\mathrm{CD}^{+} 4^{+} / \mathrm{CD} 133^{+}$cells were similar between the groups. Neither coronary artery calcification scores nor carotid intima media thickness was correlated to EPC number [52]. Lastly, Deng and colleagues [53] defined EPCs as cells positive for CD34, Dil-acLDL, and UEA and found no statistically significant difference between patients with active SLE and age- and gendermatched controls; however, there was impairment of various functional properties of cells in SLE, including proliferation, adhesion, and migration capacity, and increased expression of pro-inflammatory cytokines [53].

Other groups have also shown that EPC number, as measured by flow cytometry, is similar in SLE and controls and therefore focused on CFU formation. Grisar and colleagues [54] studied 31 females who had SLE and who were $35( \pm 2)$ years old and compared them with 14 healthy female controls who were $39( \pm 5)$ years old. The authors found no difference in $\mathrm{CD} 34^{+} / \mathrm{CD} 133^{+} / \mathrm{KDR}^{+}$ cells between SLE and controls. EPCs did appear to correlate with previous renal disease but not with other clinical parameters. The authors also reported on CFU number in 13 patients with SLE and 12 controls (ages were not reported in this subgroup) and found that CFU number was similar between the two groups. However, the authors reported a reduction in migratory and adhesive properties of cells in patients with SLE [54]. Ablin and colleagues [55] reported no significant difference in CFU number of 28 patients who had SLE and who were $38( \pm 15)$ years old and 50 controls who were 43 ( \pm 18$)$ years old. Patients with SLE included males, and patients with a history of high-dose steroid, cyclophosphamide, or mycophenolate mofetil use were excluded, suggesting that the group studied may have been of a 'milder' phenotype. The authors did note an impaired adhesion of cells to fibronectin in patients with SLE, and this was interpreted as a marker of impaired function. CFU number or adhesion scores did not vary with disease activity. Similarly, Lee and colleagues [56] enumerated CFUs from 70 patients with SLE and 31 controls who had median (interquartile range) ages of 35 (27 to 45 ) and 36 (26.5 to 44$)$ years, respectively. Ninetytwo percent of patients with SLE and 84\% of the controls were female. The authors demonstrated that the significantly reduced number of CFUs in SLE compared with controls was independent of leukopoenia. The authors also quantified $\mathrm{CD} 34^{+} / \mathrm{KDR}^{+}$cells by using flow cytometry and demonstrated a reduction in patients with SLE compared with controls. Neither CD34 $/ \mathrm{KDR}^{+}$cells nor CFUs were found to have any significant correlation to disease-related factors or CHD risk factors. However, CFUs did have an inverse correlation with C-reactive protein [56]. Ebner and colleagues [57] measured EPCs in 19 women who had SLE and who were $36( \pm 6)$ years old 
Table 1. Endothelial progenitor cell measurement in systemic lupus erythematosus

\begin{tabular}{|c|c|c|c|}
\hline $\begin{array}{l}\text { Number of patients } \\
\text { with SLE }\end{array}$ & EPC definition & Main findings & Reference \\
\hline 15 with SLE & $\mathrm{CD}^{4} 4^{+} \mathrm{KDR}^{+}$ & $\downarrow \mathrm{CD}_{3} 4^{+}, \downarrow \mathrm{CD} 34^{+} \mathrm{KDR}^{+}$in SLE & Westerweel et al. [49], 2005 \\
\hline \multirow[t]{3}{*}{15 controls } & & EPCs inversely correlated with cholesterol & \\
\hline & & $\uparrow E P C s$ in hydroxychloroquine users & \\
\hline & & $\uparrow \mathrm{CD} 4^{+}$apoptotic cells in SLE & \\
\hline \multirow{2}{*}{$\begin{array}{l}135 \text { with SLE } \\
\text { (95\% were women) }\end{array}$} & CD34/CD133+ & $\downarrow$ CD34/CD133+ in SLE & Denny et al. [50], 2007 \\
\hline & & EPCs correlated with disease activity & \\
\hline \multirow[t]{2}{*}{$\begin{array}{l}60 \text { controls } \\
\text { ( } 55 \% \text { were women) }\end{array}$} & & Impaired differentiation to EC & \\
\hline & & EPCs have increased IFN-a expression in SLE & \\
\hline 44 with SLE & $\mathrm{CD} 34 / \mathrm{CD} 133^{+}$ & $\downarrow \mathrm{CD}_{34}{ }^{+}, \mathrm{CD} 133^{+}, \mathrm{CD} 34 / \mathrm{CD} 133^{+}$in SLE & Moonen et al. [51], 2007 \\
\hline \multirow[t]{2}{*}{35 controls } & & $\downarrow$ CFUs in SLE & \\
\hline & & No correlation with SLE factors & \\
\hline 70 with SLE & CFU-Hill & $\downarrow$ CFU-Hill in SLE & Lee et al. [56], 2007 \\
\hline \multirow[t]{4}{*}{31 controls } & $\mathrm{CD} 34 / \mathrm{KDR}^{+}$ & $\downarrow C D 34 / K^{\prime} R^{+}$in SLE & \\
\hline & & EPCs inversely correlated with hsCRP & \\
\hline & & No correlation with CHD risk factors or SLE factors & \\
\hline & & High IFN-I levels associated with impaired endothelial function in SLE & \\
\hline 31 with SLE & CD34/CD133/KDR ${ }^{+}$ & $\leftrightarrow \mathrm{CD} 34 / \mathrm{CD} 133 / \mathrm{KDR}^{+}$ & Grisar et al. [54], 2008 \\
\hline 14 controls & CFU-Hill & $\leftrightarrow$ CFU-Hill & \\
\hline 28 with SLE & CFU-Hill & $\leftrightarrow$ CFU-Hill & Ablin et al. [55], 2010 \\
\hline 50 controls & & No correlation with CHD risk factors or SLE factors & \\
\hline 19 with SLE & $\mathrm{KDR} / \mathrm{CD} 133^{+} \mathrm{CD} 34 / \mathrm{KDR}^{+}$ & $\downarrow C D 34 / K^{\prime} R^{+}$in SLE & Ebner et al. [57], 2010 \\
\hline \multirow[t]{2}{*}{19 controls } & Late-outgrowth colonies & $\uparrow \mathrm{KDR} / \mathrm{CD} 133^{+}$in SLE & \\
\hline & & $\leftrightarrow$ Late-outgrowth colonies & \\
\hline \multirow{2}{*}{$\begin{array}{l}17 \text { with SLE } \\
\text { (100\% were women) }\end{array}$} & CD34/CD133/KDR ${ }^{+}$ & $\downarrow \mathrm{CD} 34 / \mathrm{CD} 133 / \mathrm{KDR}^{+}$in SLE & Baker et al. [52], 2011 \\
\hline & $\mathrm{CD} 34 / \mathrm{CD} 133^{+}$ & $\leftrightarrow \mathrm{CD} 34 / \mathrm{CD} 133^{+}$ & \\
\hline $\begin{array}{l}13 \text { controls } \\
\text { (38\% were women) }\end{array}$ & & No correlation with coronary artery calcification score in SLE & \\
\hline 35 with active SLE & Late-outgrowth colonies & $\leftrightarrow$ CD34/Dil-acLDL/UEA & Deng et al. [53], 2010 \\
\hline \multirow[t]{2}{*}{35 controls } & CD34/Dil-acLDL/ UEA & $\downarrow$ proliferation, adhesion, and migration in SLE & \\
\hline & & No correlation with SLE factors & \\
\hline
\end{tabular}

$\uparrow$, increase in; $\downarrow$, decrease in; $\leftrightarrow$, no change in; CFU, colony-forming unit; CHD, coronary heart disease; Dil-acLDL, Dil-labeled acetylated low-density lipoprotein; EC, endothelial cell; EPC, endothelial progenitor cell; hsCRP, high-sensitivity C-reactive protein; IFN-a, interferon-alpha; KDR, kinase insert domain receptor; SLE, systemic lupus erythematosus; UEA, Ulex europaeus agglutinin.

and in 19 female controls who were $37( \pm 8)$ years old. The authors demonstrated reduced $\mathrm{CD}^{2} 4^{+} / \mathrm{KDR}^{+}$cells in

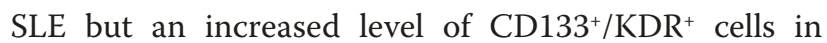
comparison with controls. Clinical correlates were not analyzed. The authors suggested that low levels of endothelial damage may result in increased mobilization of immature $\mathrm{CD} 133^{+} / \mathrm{KDR}^{+}$cells.

Overall, studies of EPCs measured by using flow cytometry have consistently demonstrated a reduction in $\mathrm{CD} 34^{+} / \mathrm{KDR}^{+}$cells in comparison with controls
$[49,56,57]$. Two studies have also demonstrated a reduction in CD34/CD133+ cells [50,51]. Grisar and colleagues [54] measured the smaller population of $\mathrm{CD} 34^{+} / \mathrm{CD}^{2} 33^{+} /$ $\mathrm{KDR}^{+}$cells and found no difference between SLE and controls. It may be that CD133 expression is rapidly lost in this population of cells. Similarly, our group found no difference in the number of CD $34^{+} / \mathrm{CD} 133^{+}$cells between 56 patients with SLE and 48 healthy matched controls $(0.03 \%( \pm 0.02 \%)$ versus $0.02 \%( \pm 0.02 \%), P=$ not significant) but did demonstrate a significant reduction of 
CFUs in patients with SLE $(7( \pm 6)$ versus $12( \pm 12)$, $P=0.05)$. Neither CFUs nor $\mathrm{CD} 34^{+} / \mathrm{CD} 133^{+}$cells were related to SLE or CHD risk factors [58].

Possible explanations for the discrepancy of the findings between different studies may be related to small sample sizes, differences within the study population, or method of EPC isolation and identification. A crucial consideration is the difference in the methodology used by different groups to quantify cells. Some groups have included absolute counts per volume of blood [49], whereas others have measured percentage of the mononuclear cell population [54]. Most EPC quantification methods using flow cytometry identify cells within the lymphocyte gate or involve a lymphocyte separation step. However, lymphopenia among patients with SLE may possibly result in an over- or underestimation of EPCs in this condition. In contrast, it is also possible that cytopenias may result in bone marrow stimulation and the increased production of progenitor cells.

The results of culture studies have been more consistent, and whereas some studies have had small sample sizes, the larger of these studies [56] demonstrated a reduction in CFUs in SLE compared with controls. The smallest of the studies [51] included patients with a mild phenotype and did not find any difference in CFU number in patients with SLE, suggesting that CFU number may be related to overall inflammatory burden over time. The discordance between findings using CFUs and EPCs may provide complementary rather than contradictory results. It is likely that CFUs measure a distinct myeloid-derived cell (now termed earlyoutgrowth EPC) compared with the population of CD34. or $\mathrm{CD}_{133^{+}}$cells measured by using flow cytometry, and this may explain the discrepancy observed when these two measures were used. CFU measures are also likely, to some extent, to be a reflection of EPC functional ability to migrate to a cluster of cells and adhere to fibronectin. It may well be that, while progenitors are generated in adequate numbers by patients with SLE, their ability to mature and function differs from healthy individuals, resulting in fewer effective cells in patients with SLE and thus contributing to increased endothelial dysfunction. This hypothesis is supported by the observation that the migratory and proliferative capacities of EPCs are both reduced in SLE $[54,57]$.

Studies in SLE to date have been too small to detect clinical correlates to EPCs or CFUs. All studies have been cross-sectional and primarily included patients with quiescent disease, although some groups have selected patients with active disease for study; however, the influence of inflammatory burden over time or vasculitic manifestations remains unclear. The effect of anti-metabolite therapies such as azathioprine and mycophenolate remains unclear, and it is possible that these drugs may be toxic to $\mathrm{CD}^{+} 4^{+}$cells. Furthermore, Grisar and colleagues [54] documented EPC dysfunction in patients receiving anti-malarial therapy, although the small sample size makes robust conclusions difficult.

\section{Interferon-alpha, endothelial progenitor cells, and systemic lupus erythematosus}

An interesting link between interferon-alpha (IFN- $\alpha$ ) and EPCs is emerging within the SLE literature and may provide a mechanistic explanation for some observations. IFN- $\alpha$ is a member of the type 1 IFN cytokine family. These proteins have a role in immune defense, and increased levels are observed in the context of viral infections. They also have a role in physiological growth and differentiation [59]. IFN- $\alpha$ has been demonstrated to inhibit angiogenesis and vascular tumor growth [60]. Increased levels of IFN- $\alpha$ can be detected during a flare in SLE and have a central role in SLE pathogenesis [61]. Direct quantification assays of IFN are unreliable, and therefore downstream effects of IFN are used as surrogate markers. Lee and colleagues [56] demonstrated a reduction of CFU formation in those SLE patients with high expression of the IFN-I-stimulated gene $M X 1(\mathrm{n}=19)$ and an inverse correlation of MXI with CFUs. Importantly, high IFN-I levels were associated with impaired endothelial function as measured by using peripheral arterial plathysmography [56]. Similarly, Denny and colleagues [50] demonstrated that supernatant from SLE ECs caused increased induction of IFN-inducible genes in comparison with healthy controls. Furthermore, the addition of recombinant IFN- $\alpha$ had a toxic effect on $\mathrm{CD} 133^{+}$cells in culture, resulting in CD133/CD34+ apoptosis. The authors used an anti-IFN- $\alpha$ monocloncal antibody to block IFN pathways in SLE EPCs in culture and demonstrated a normalization of function [50]. In addition, studies from the Kaplan laboratory [62] enabled the proposal of an interesting concept by using data from NZB/W lupus-prone mice: the authors showed that type I IFNs may play an important role in premature vascular damage and, potentially, atherosclerosis development in SLE. Based on the findings from a study by Lian and colleagues [63], they suggest that the bone marrow niche may be exposed to elevated levels of IFN more than other peripheral compartments and that this, in turn, could effect EPC properties with regard to their mobilization and homing to damaged tissue [63]. These early observations require further investigation as they may provide a pathway to restoration of EC function in SLE.

\section{Implications and future directions}

Initial findings from studies suggest the potential use of EPCs as a novel biomarker in risk stratification of CHD or some insight into future organ-specific therapeutic targets in SLE. However, many questions remain 
unanswered. Larger studies are required to verify these preliminary results and provide robust conclusions, in particular, to ascertain the influence of drugs such as statins. Longitudinal studies that focus on assessment before and after commencement of anti-metabolite therapies are needed. Given the low prevalence of SLE and diversity of clinical manifestations and therefore exposures, it is envisaged that multi-center collaborations should be encouraged.

Several groups have demonstrated reduced EPCs as measured by culture methods in SLE, but the precise characterization of EPCs requires further clarification of the mechanisms underpinning abnormalities in EC function (for example, homing signals to sites of damaged endothelium require further investigation). To date, studies have compared patients with SLE with healthy controls. However, a more relevant comparison group may be a cohort with another chronic inflammatory condition to elucidate the relative contribution to atherosclerosis in SLE.

Studies have suggested that type I IFN may contribute to EPC dysfunction in SLE and may suggest a potential role for their rescue by type I IFN-blocking agents (either IFN-antagonizing antibodies or receptor blockers) currently under development. Implications of promoting vasculogenesis/blocking type I IFN, however, need to be considered in the wider clinical context. There is potential for exacerbation of viral diseases or retinopathies. Also, the effect on tumor formation in this vulnerable patient group or the effect on manifestations such as inflammatory arthritis, in which it is thought that pathological angiogenesis occurs, is unknown.

Laboratory observations to date would suggest that there is an excess of EPC dysfunction in SLE, and clinical studies in the 'general' population would suggest that this can be of relevance to clinical coronary events. However, within SLE, prospective studies using clinical outcomes are required (a) to determine the consequence of low EPC number, (b) to establish whether the ex vivo situation is of relevance and reflects in vivo effects, (c) to determine whether low EPC number does contribute to an excess of CHD, and (d) to assess whether therapeutic targeting of EPCs will enhance vascular repair and improve long-term outcomes in SLE.

\section{Abbreviations \\ CFU, colony-forming unit; CHD, coronary heart disease; Dil-aCLDL, Dil-labeled acetylated low-density lipoprotein; EC, endothelial cell; EPC, endothelial progenitor cell; IFN-a, interferon-alpha; KDR, kinase insert domain receptor; SLE, systemic lupus erythematosus; VEGF, vascular endothelial growth factor; VEGFR2, vascular endothelial growth factor receptor-2.}

\section{Competing interests}

INB has received honoraria, speakers fees and grant income from several companies including UCB and Roche (grant income) GSK, Human Genome Sciences, Roche, Pfizer, BMS, Reimmunix, Medimmune and Astra Zeneca (speaker and consulting fees).

\section{Author details}

'Arthritis Research UK Epidemiology Unit, School of Translational Medicine, Manchester Academic Health Science Centre, The University of Manchester Oxford Road, Manchester, M13 9PT, UK. ²Department of Rheumatology, East Lancashire Hospitals Trust, Haslingden Road, Blackburn, BB2 3HH, UK

${ }^{3}$ Cardiovascular Sciences Group, School of Biomedicine, Manchester Academic Health Science Centre, The University of Manchester, 46 Grafton Street,

Manchester, M13 9NT, UK. ${ }^{4}$ The Kellgren Centre for Rheumatology, Manchester NIHR Biomedical Research Centre, Central Manchester University Hospitals NHS Foundation Trust, Oxford Road, Manchester, M13 9WL, UK.

Published: 20 February 2012

References

1. Urowitz MB, Bookman AA, Koehler BE, Gordon DA, Smythe HA, Ogryzlo MA: The bimodal mortality pattern of systemic lupus erythematosus. Am J Med 1976, 60:221-225.

2. Manzi S, Meilahn EN, Rairie JE, Conte CG, Medsger TA Jr., Jansen-McWilliams L, D'Agostino RB, Kuller LH: Age-specific incidence rates of myocardial infarction and angina in women with systemic lupus erythematosus: comparison with the Framingham Study. Am J Epidemiol 1997, 145:408-415.

3. Ward MM: Premature morbidity from cardiovascular and cerebrovascular diseases in women with systemic lupus erythematosus. Arthritis Rheum 1999, 42:338-346.

4. Esdaile JM, Abrahamowicz M, Grodzicky T, Li Y, Panaritis C, du Berger R, Côte R, Grover SA, Fortin PR, Clarke AE, Senécal JL: Traditional Framingham risk factors fail to fully account for accelerated atherosclerosis in systemic lupus erythematosus. Arthritis Rheum 2001, 44:2331-2337.

5. El-Magadmi M, Bodill H, Ahmad Y, Durrington PN, Mackness M, Walker M, Bernstein RM, Bruce IN: Systemic lupus erythematosus: an independent risk factor for endothelial dysfunction in women. Circulation 2004 110:399-404.

6. Hansson GK: Inflammation, atherosclerosis, and coronary artery disease. NEngl J Med 2005, 352:1685-1695.

7. Werner N, Kosiol S, Schiegl T, Ahlers P, Walenta K, Link A, Böhm M, Nickenig G: Circulating endothelial progenitor cells and cardiovascular outcomes. NEngl J Med 2005, 353:999-1007.

8. Ingram DA, Mead LE, Moore DB, Woodard W, Fenoglio A, Yoder MC: Vessel wall-derived endothelial cells rapidly proliferate because they contain a complete hierarchy of endothelial progenitor cells. Blood 2005, 105:2783-2786.

9. Holmén C, Elsheikh E, Stenvinkel P, Qureshi AR, Pettersson E, Jalkanen S, Sumitran-Holgersson S: Circulating inflammatory endothelial cells contribute to endothelial progenitor cell dysfunction in patients with vasculitis and kidney involvement. J Am Soc Nephrol 2005, 16:3110-3120.

10. Asahara T, Murohara T, Sullivan A, Silver M, van der Zee R, Li T, Witzenbichler B, Schatteman G, Isner JM: Isolation of putative progenitor endothelial cells for angiogenesis. Science 1997, 275:964-967.

11. Asahara T, Takahashi T, Masuda H, Kalka C, Chen D, Iwaguro H, Inai Y, Silver M, Isner JM: VEGF contributes to postnatal neovascularization by mobilizing bone marrow-derived endothelial progenitor cells. EMBO J 1999. 18:3964-3972.

12. Khan SS, Solomon MA, McCoy JP Jr.: Detection of circulating endothelial cells and endothelial progenitor cells by flow cytometry. Cytometry B Clin Cytom 2005, 64:1-8.

13. Timmermans F, Plum J, Yoder MC, Ingram DA, Vandekerckhove B, Case J: Endothelial progenitor cells: identity defined? J Cell Mol Med 2009, 13:87-102

14. Cheng J, Baumhueter S, Cacalano G, Carver-Moore K, Thibodeaux H, Thomas R, Broxmeyer HE, Cooper S, Haque N, Moore M, Lasky LA: Hematopoietic defects in mice lacking the sialomucin CD34. Blood 1996, 87:479-490.

15. Yin AH, Miraglia S, Zanjani ED, Almeida-Porada G, Ogawa M, Leary AG, Olweus J, Kearney J, Buck DW: AC133, a novel marker for human hematopoietic stem and progenitor cells. Blood 1997, 90:5002-5012.

16. Peichev M, Naiyer AJ, Pereira D, Zhu Z, Lane WJ, Williams M, Oz MC, Hicklin DJ, Witte L, Moore MA, Rafii S: Expression of VEGFR-2 and AC133 by circulating human CD34(+) cells identifies a population of functional endothelial precursors. Blood 2000, 95:952-958.

17. Roskoski R Jr.: VEGF receptor protein-tyrosine kinases: structure and regulation. Biochem Biophys Res Commun 2008, 375:287-291.

18. Woodfin A, Voisin MB, Nourshargh S. PECAM-1: a multi-functional molecule 
in inflammation and vascular biology. Arterioscler Thromb Vasc Biol 2007 27:2514-2523.

19. Denis CV: Molecular and cellular biology of von Willebrand factor. Int J Hematol 2002, 75:3-8.

20. Watt SM, Gschmeissner SE, Bates PA: PECAM-1: its expression and function as a cell adhesion molecule on hemopoietic and endothelial cells. Leuk Lymphoma 1995, 17:229-244.

21. Fernandez Pujol B, Lucibello FC, Gehling UM, Lindemann K, Weidner N, Zuzarte ML, Adamkiewicz J, Elsässer HP, Müller R, Havemann K: Endotheliallike cells derived from human CD14 positive monocytes. Differentiation 2000, 65:287-300.

22. Romagnani P, Annunziato F, Liotta F, Lazzeri E, Mazzinghi B, Frosali F, Cosmi L, Maggi L, Lasagni L, Scheffold A, Kruger M, Dimmeler S, Marra F, Gensini G,Maggi E, Romagnani S: CD14+CD34low cells with stem cell phenotypic and functional features are the major source of circulating endothelial progenitors. Circ Res 2005, 97:314-322.

23. Abu El-Asrar AM, Struyf S, Verbeke H, Van Damme J, Geboes K: Circulating bone-marrow-derived endothelial precursor cells contribute to neovascularization in diabetic epiretinal membranes. Acta Ophthalmol 2011, 89:222-228

24. Pelliccia F, Pasceri V, Cianfrocca C, Vitale C, Pristipino C, Speciale G, Mercuro G, Rosano G: Endothelial progenitor cells in patients with coronary artery disease and left ventricular dysfunction. Coron Artery Dis 2009, 20:303-308

25. HuT, She Q, Jiang Y, Su L, Yin Y: Level of CD14+-endothelial progenitor cells is not associated with coronary artery disease or cardiovascular risk factors. Age (Dordr) 2008, 30:319-326.

26. Hill JM, Zalos G, Halcox JP, Schenke WH, Waclawiw MA, Quyyumi AA, Finkel T: Circulating endothelial progenitor cells, vascular function, and cardiovascular risk. N Engl J Med 2003, 348:593-600.

27. Lin Y, Weisdorf DJ, Solovey A, Hebbel RP: Origins of circulating endothelial cells and endothelial outgrowth from blood. J Clin Invest 2000, 105:71-77.

28. Prokopi M, Mayr M: Proteomics: a reality-check for putative stem cells. Circ Res 2011, 108:499-511.

29. Jialal I, Fadini GP, Pollock K, Devaraj S: Circulating levels of endothelial progenitor cell mobilizing factors in the metabolic syndrome. Am J Cardiol 2010, 106:1606-1608.

30. Jodon de Villeroché V, Avouac J, Ponceau A, Ruiz B, Kahan A, Boileau C, Uzan $G$, Allanore Y: Enhanced late-outgrowth circulating endothelial progenitor cell levels in rheumatoid arthritis and correlation with disease activity. Arthritis Res Ther 2010, 12:R27.

31. Urbich C, De Souza Al, Rossig L, Yin X, Xing Q, Prokopi M, Drozdov I, Steiner M, Breuss J, Xu Q, Dimmeler S, Mayr M: Proteomic characterization of human early pro-angiogenic cells. J Mol Cell Cardiol 2011, 50:333-336.

32. Ingram DA, Caplice NM, Yoder MC: Unresolved questions, changing definitions, and novel paradigms for defining endothelial progenitor cells. Blood 2005, 106:1525-1531.

33. Rohde E, Bartmann C, Schallmoser K, Reinisch A, Lanzer G, Linkesch W, Guelly C, Strunk D: Immune cells mimic the morphology of endothelial progenitor colonies in vitro. Stem Cells 2007, 25:1746-1752.

34. Desai A, Glaser A, Liu D, Raghavachari N, Blum A, Zalos G, Lippincott M, McCoy JP, Munson PJ, Solomon MA, Danner RL, Cannon RO 3rd: Microarraybased characterization of a colony assay used to investigate endothelial progenitor cells and relevance to endothelial function in humans. Arterioscler Thromb Vasc Biol 2009, 29:121-127.

35. Rehman J, Li J, Orschell CM, March KL: Peripheral blood "endothelial progenitor cells" are derived from monocyte/macrophages and secrete angiogenic growth factors. Circulation 2003, 107:1164-1169.

36. Burt RK, Testori A, Oyama Y, Rodriguez HE, Yaung K, Villa M, Bucha JM, Milanetti F, Sheehan J, Rajamannan N, Pearce WH: Autologous peripheral blood CD133+ cell implantation for limb salvage in patients with critical limb ischemia. Bone Marrow Transplant 2010, 45:111-116.

37. Kawamura A, Horie T, Tsuda I, Abe Y, Yamada M, Egawa H, Iida J, Sakata H, Onodera K, Tamaki T, Furui H, Kukita K, Meguro J, Yonekawa M, Tanaka S: Clinical study of therapeutic angiogenesis by autologous peripheral blood stem cell (PBSC) transplantation in 92 patients with critically ischemic limbs. J Artif Organs 2006, 9:226-233.

38. Hernández P, Cortina L, Artaza H, Pol N, Lam RM, Dorticós E, Macías C, Hernández C, del Valle L, Blanco A, Martínez A, Díaz F: Autologous bonemarrow mononuclear cell implantation in patients with severe lower limb ischaemia: a comparison of using blood cell separator and Ficoll density gradient centrifugation. Atherosclerosis 2007, 194:e52-e56.
39. Assmus B, Rolf A, Erbs S, Elsässer A, Haberbosch W, Hambrecht R, Tillmanns H Yu J, Corti R, Mathey DG, Hamm CW, Süselbeck T, Tonn T, Dimmeler S, Dill T, Zeiher AM, Schächinger V; REPAIR-AMI Investigators: Clinical outcome 2 years after intracoronary administration of bone marrow-derived progenitor cells in acute myocardial infarction. Circ Heart Fail 2010, 3:89-96

40. Bartunek J, Vanderheyden M, Vandekerckhove B, Mansour S, De Bruyne B, De Bondt P, Van Haute I, Lootens N, Heyndrickx G, Wijns W: Intracoronary injection of CD133-positive enriched bone marrow progenitor cells promotes cardiac recovery after recent myocardial infarction: feasibility and safety. Circulation 2005, 112 (9 Suppl):1178-1183.

41. Kirton JP, Xu Q: Endothelial precursors in vascular repair. Microvasc Res 2010, 79:193-199.

42. Kondo T, Hayashi M, Takeshita K, Numaguchi Y, Kobayashi K, lino S, Inden Y, Murohara T: Smoking cessation rapidly increases circulating progenitor cells in peripheral blood in chronic smokers. Arterioscler Thromb Vasc Biol 2004, 24:1442-1447.

43. Lenk K, Uhlemann M, Schuler G, Adams V: Role of endothelial progenitor cells in the beneficial effects of physical activity on atherosclerosis and coronary artery disease. J Appl Physiol 2011, 111:321-328.

44. Reinhard H, Jacobsen PK, Lajer M, Pedersen N, Billestrup N, Mandrup-Poulsen T, Parving HH, Rossing P: Multifactorial treatment increases endothelial progenitor cells in patients with type 2 diabetes. Diabetologia 2010, 53:2129-2133

45. Muller P, Kazakov A, Jagoda P, Semenov A, Bohm M, Laufs U: ACE inhibition promotes upregulation of endothelial progenitor cells and neoangiogenesis in cardiac pressure overload. Cardiovasc Res 2009, 83:106-114.

46. Gill M, Dias S, Hattori K, Rivera ML, Hicklin D, Witte L, Girardi L, Yurt R, Himel H, Rafii S: Vascular trauma induces rapid but transient mobilization of VEGFR2+AC133+ endothelial precursor cells. Circ Res 2001, 88:167-174.

47. Yip HK, Tsai TH, Lin HS, Chen SF, Sun CK, Leu S, Yuen CM, Tan TY, Lan MY, Liou CW, Lu CH, Chang WN: Effect of erythropoietin on level of circulating endothelial progenitor cells and outcome in patients after acute ischemic stroke. Crit Care 2011, 15:R40.

48. Vasa M, Fichtlscherer S, Aicher A, Adler K, Urbich C, Martin H, Zeiher AM, Dimmeler S: Number and migratory activity of circulating endothelial progenitor cells inversely correlate with risk factors for coronary artery disease. Circ Res 2001, 89:E1-E7.

49. Westerweel PE, Luijten RK, Hoefer IE, Koomans HA, Derksen RH, Verhaar MC: Haematopoietic and endothelial progenitor cells are deficient in quiescent systemic lupus erythematosus. Ann Rheum Dis 2007, 66:865-870

50. Denny MF, Thacker S, Mehta H, Somers EC, DodickT, Barrat FJ, McCune WJ, Kaplan MJ: Interferon-\{alpha\} promotes abnormal vasculogenesis in lupus: a potential pathway for premature atherosclerosis. Blood 2007, 110:2907-2915.

51. Moonen JR, de Leeuw K, van Seijen XJ, Kallenberg CG, van Luyn MJ, Bijl M, Harmsen MC: Reduced number and impaired function of circulating progenitor cells in patients with systemic lupus erythematosus. Arthritis Res Ther 2007, 9:R84.

52. Baker JF, Zhang L, Imadojemu S, Sharpe A, Patil S, Moore JS, Mohler ER 3rd, Von Feldt J: Circulating endothelial progenitor cells are reduced in SLE in the absence of coronary artery calcification. Rheumatol Int 2011 Jan 19 [Epub ahead of print].

53. Deng XL, Li XX, Liu XY, Sun L, Liu R: Comparative study on circulating endothelial progenitor cells in systemic lupus erythematosus patients at active stage. Rheumatol Int 2010, 30:1429-1436.

54. Grisar J, Steiner CW, Bonelli M, Karonitsch T, Schwarzinger I, Weigel G, Steiner G, Smolen JS: Systemic lupus erythematosus patients exhibit functional deficiencies of endothelial progenitor cells. Rheumatology 2008, 47:1476-1483.

55. Ablin JN, Boguslavski V, Aloush V, Elkayam O, Paran D, Levartovski D, Caspi D, George J: Enhanced adhesive properties of endothelial progenitor cells (EPCS) in patients with SLE. Rheumatol Int 2011, 31:773-778.

56. Lee PY, Li Y, Richards HB, Chan FS, Zhuang H, Narain S, Butfiloski EJ, Sobel ES, Reeves WH, Segal MS: Type I interferon as a novel risk factor for endothelia progenitor cell depletion and endothelial dysfunction in systemic lupus erythematosus. Arthritis Rheum 2007, 56:3759-3769.

57. Ebner P, Picard F, Richter J, Darrelmann E, Schneider M, Strauer BE, Brehm M: Accumulation of VEGFR-2+/CD133+ cells and decreased number and impaired functionality of CD34+/NEGFR-2+ cells in patients with SLE. Rheumatology (Oxford) 2010, 49:63-72. 
58. Haque S, Rakieh C, Parker B, Jackson M, Day P, Alexander YM, Bruce IN: Endothelial cell abnormalities in SLE. Lupus 2010, 19 (1 suppl):1-185.

59. Hall JC, Rosen A: Type I interferons: crucial participants in disease amplification in autoimmunity. Nat Rev Rheumatol 2010, 6:40-49.

60. Lindner DJ: Interferons as antiangiogenic agents. Curr Oncol Rep 2002, 4:510-514.

61. Banchereau J, Pascual V: Type I interferon in systemic lupus erythematosus and other autoimmune diseases. Immunity 2006, 25:383-392.

62. Thacker SG, Duquaine D, Park J, Kaplan MJ: Lupus-prone New Zealand Black/New Zealand White F1 mice display endothelial dysfunction and abnormal phenotype and function of endothelial progenitor cells. Lupus 2010, 19:288-299
63. Lian ZX, Kikuchi K, Yang GX, Ansari AA, Ikehara S, Gershwin ME: Expansion of bone marrow IFN-alpha-producing dendritic cells in New Zealand Black (NZB) mice: high level expression of TLR9 and secretion of IFN-alpha in NZB bone marrow. J Immunol 2004, 173:5283-5289.

doi:10.1186/ar3700

Cite this article as: Haque S, et al.: Endothelial progenitor cells: a new player in lupus? Arthritis Research \& Therapy 2012, 14:203. 